\title{
The Pressure Loss Calculation Method and Application of Portable Fire Extinguishing Equipment for Power System
}

\author{
J.Z. Lu, T.J. Zhou, B. Li, C.P.Wu, Y. Liu \\ Power transmission and distribution equipment anti-icing \& reducing disaster technology key lab of state grid in China \\ China
}

\begin{abstract}
Wildfire nearby transmission has posed a serious threat on power system. Research on portable fire extinguishing equipment hasimportantsignificance to massive wildfire emergency handling. Structure of the water transfer system of the portable fire extinguishing equipmentis analysed. Pressure lossforms of the equipment are elaborated. Basing onactual instance of the water transfer system, a calculation method of pressure loss for long-distance and high-lift transmission is proposed.With the result of the test and CFD simulation, the efficiency and the practicability of the method is verified. A conclusionthat transportation distance reaches close to 3000 meterswhilehead reaches 500 meters is drawn. Finally,the application of the portable fire extinguishing equipment in fire prevention of power transmission line results show thatmassive wildfires can be extinguished quickly.By using the equipment, electric power company's ability of resisting wildfires has gained remarkable improvement.
\end{abstract}

Keywords-wildfire;portable fire extinguishing equipment; pressure loss; transportation distance; head

\section{INTRODUCTION}

With complex climatic conditions, influenced by human interference activities such as spring ploughing, Chinese New Year celebrations, ceremonies during Ching Ming festival and autumn harvest, frequent occurrences of fires disasters near transmission in recent years have caused major property losses in the China's grid company.Wildfires near transmission not only harm the electric equipment, but also threaten stability of the power system. Trips caused by wildfire at the same time or in successionmay cause large area power cuttingor breakdown of power network. Control the fire as quickly as possible can stop the fire spreading to transmission.

Currently,the development and improvementof firefighting equipment have been paid widely attention to by researchers at home and abroad.This research results have provided effective methods for fire control[1-4]. As the wildfires disperse in many spotsand quite wide areas,combined that ashes are easy to reburnin the wild, the control of wildfires near transmission is carried into effect difficultly.In areas deficient of water, portablefire-fighting equipmentshould not be used for massive fires.Although fire trucks could carry plenty of water, they are not is unsuitable for wildfires near transmission, due to the traffic inconvenience and low outlet pressure.
Water-series extinguisheris piped tohigh pressure water mist nozzleby the high pressure piston pumpof portable fire extinguishing equipmentfor power system(referred to in this article portable fire extinguishing equipment).Security of firefighting crews will be threatenedand anti-fire efficiencyis weakif the location of fires may beyond the range oftransportation distance and head. So, transportation distance and head are the important parameters of portable fire extinguishing equipment.The pressure loss of water-series extinguisher in the pipelinesaffectedthose two parametersmarkedly. A study on the calculation methods of pressure loss is significant in improving the science and correctness of firefighting workeffectively.

\section{PRESSURE LOSS FORMS OF PORTABLE FIRE EXTINGUISHING EQUIPMENT}

The water conveyance system of portable fire extinguishing equipmentincludeshigh pressure piston pump, connecting pipe, pressure regulating valve, pressure relief valve, fire hose,elbows, and high pressure water mist nozzle, as shown in figure 1.

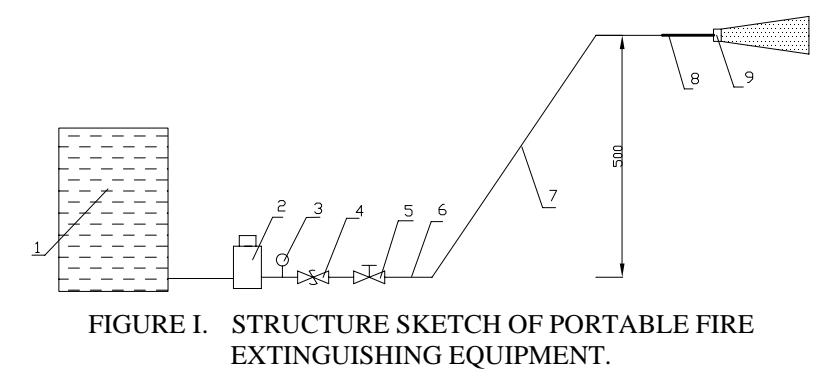

1-water tank; 2-high pressure piston pump; 3-piezometer; 4safety valve; 5-pressure regulating valve; 6- truckmountedconnecting pipe; 7-fire hose; 8-lance; 9-high pressure water mist nozzle

By applying the Bernoulli equation, which is shown as formula (1),pressure loss of portable fire extinguishing equipmentincludesthe route loss and the local loss.

$$
z_{1}+\frac{p_{1}}{\rho g}+\alpha_{1} \frac{v_{1}}{2 g}=z_{2}+\frac{p_{2}}{\rho g}+\alpha_{2} \frac{v_{2}}{2 g}(1)
$$

From formula (1) and figure 1, the pressure loss forms of the equipment can be drawn, as shown in figure 2 . 


$$
h_{s d}=\lambda \times \frac{L}{d} \times \frac{1}{2 g} \times v^{2}+\sum \varsigma_{i} \times \frac{1}{2 g} \times v_{i}^{2}(2)
$$

Where, $L$ is the length of fire hose, $d$ is internal diameter of fire hose, $\lambda$ is the friction factor, $\varsigma_{i}$ islocal drag coefficient and vdenotes a mean velocity of the fluid in the conduit.

\section{PRESSURE LOSS CALCULATION AND SIMULATION OF PORTABLE FIRE EXTINGUISHING EQUIPMENT}

\section{A. Flow Analysis ofWater-series Extinguisher}

Reynolds number is an important parameter reflecting the fluid flow characteristics in the pipe. When the Reynolds number is small, viscous forces plays host tothe force between liquid particles and a fluid flows in parallel layers, with no disruption between the layers. While if the Reynolds number is large, the flowing liquid is in a turbulence state, thusinertiaforces plays host tothe force between liquid particles.

The sectional areaand velocityequals everywherealong the fire hose.Formula 3is commonly used for calculationof velocity of flow.

$$
\mathrm{v}=\frac{4 Q}{\pi d^{2}}(3)
$$

So, if the average flow of fire hose is 20.3 litres per minute and the diameterof pipeline is $16 \mathrm{~mm}$, thenvelocity of water-series extinguisher is $1.659 \mathrm{~m} / \mathrm{s}$.

At $20^{\circ} \mathrm{C}$, the dynamic viscosity of water-series extinguisheris $1.005 \times 10^{-3} \mathrm{pa} \cdot \mathrm{s}$.According to the formula of calculationof Reynolds number,it can be deduced thatthe Reynolds number is 26411 and the flowing liquid is in a turbulence state,

\section{B. Calculation of the Route Loss}

The inner surface roughness of the fire hosemeasures $0.010 \mathrm{~mm}$ and the relative roughness is 0.000625.Thicknessviscous sub-layer is calculated using semiempirical correlation, as shown in formula4.

$$
\delta=\frac{34.2 \mathrm{~d}}{\mathrm{Re}^{0.875}}=7.39 \times 10^{-2}>\Delta=0.010 \mathrm{~mm}(4)
$$

This shows that the fire hose is hydraulic smooth pipe at this condition. So, the water-series extinguisher flow conditioncorresponds tothe third interval of Nicholas' curve.Iterative method was used to calculate the friction factorin Prandtl-Schlichtingformula which is shown in formula 5.

$$
\frac{1}{\sqrt{\lambda}}=-2.01 \mathrm{~g}\left(\frac{2.51}{\operatorname{Re} \sqrt{\lambda}}\right)(5)
$$

Take the Reynolds number Re into (5) perform iterative calculation, then get that $\lambda=0.0241$.

Using formula (2) gains that the frictional head loss of $3000 \mathrm{~m}$ pipe is $621 \mathrm{~m}$ (water column height), that is the frictional head loss of $3000 \mathrm{~m}$ pipe is $6.21 \mathrm{MPa}$.
Simulate the waterdelivery system of portable fire extinguishing equipment based on Fluent6.3.26, use periodic boundary conditions[5], calculate the pressure loss of unit length of water pipe under a certain flow, then, we can get the frictional pressure loss of $3000 \mathrm{~m}$ pipe. Aiming to the Reynolds number Re of fluid flowing in the pipe, calculate by using Spalsrt-Allmaras model and $\kappa-\varepsilon$ model[6,7] respectively, and compare the result of numerical modelling with that of calculation following Nikuradse experience curve method.

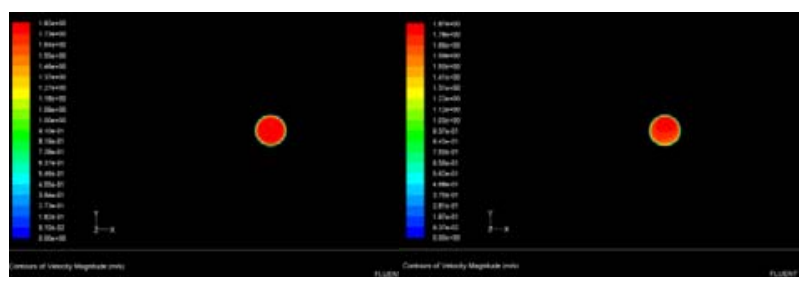

FIGURE II. VELOCITY DISTRIBUTION THROUGH ANALOG CALCULATION BY USING S-A MODEL AND $\kappa-\varepsilon$ MODEL.

TABLE I. PRESSURE LOSS UNDER DIFFERENT TURBULENCE MODEL.

\begin{tabular}{|l|l|l|}
\hline calculation model & Pressure Lose & Error \\
\hline Nikuradse Curve & $6.21 \mathrm{MPa}$ & \\
\hline Spalsrt-Allmaras Model & $7.20 \mathrm{MPa}$ & $15.9 \%$ \\
\hline$\kappa-\varepsilon$ Model & $8.40 \mathrm{MPa}$ & $35.26 \%$ \\
\hline RNG $-\varepsilon$ Model & $7.25 \mathrm{MPa}$ & $16.7 \%$ \\
\hline
\end{tabular}

Table 1 indicates that Spalsrt-Allmaras Model is more accurate to simulate the pressure loss of the portable fire extinguishing equipment than others, whose calculation accuracy could satisfy the requirement of design and application of portable fire extinguishing equipment. The reason is that Spalsrt-Allmaras Model is effective to simulate low Reynolds number flow, and its' demand on grid partition is not high. According to Fig3, the velocitygradient near wall in Spalsrt-Allmaras Model is smaller than that in $\kappa-\varepsilon$ Model. Turbulent fluctuation contributes to dramatic power exchange among the particle of fire extinguishing agent and uniform distribution of velocity, which better meets the velocity distribution formula 6 of fluid in the core of turbulence in hydraulically smooth region.

$$
\frac{u}{u *}=2.5 \ln \frac{u \cdot y}{v}+5.5
$$

\section{Local Loss Analysis}

The local loss is due to the change of the water hose sectional area, which causes the change of flow direction, the redistribution of velocity and the loss resulting from the momentum exchange among mass points by collision. The local loss of the water delivery system of mobile fire-fighting platform includes 5 forms, among which are sudden expansion, sudden contraction, bend, folded hose and sluice valve. 
TABLE II. LOCAL LOSS CALCULATION OF PORTABLE FIRE EXTINGUISHING EQUIPMENT.

\begin{tabular}{|c|c|c|c|}
\hline No. & form of Loss & Local loss coefficient & local pressure loss \\
\hline 1 & $\begin{array}{c}\text { Diameter } \\
\text { expanding }\end{array}$ & $\varsigma_{1}=\left(1-\frac{A_{1}}{A_{2}}\right)^{2}$ & $\mathrm{~h}_{1}=\varsigma_{1} \times \frac{1}{2 g} \times v_{1}^{2}$ \\
\hline 2 & $\begin{array}{c}\text { Diameter } \\
\text { reduction }\end{array}$ & $\varsigma_{2}=\frac{1}{2}\left(1-A_{2} / A_{1}\right)$ & $\mathrm{h}_{2}=\varsigma_{2} \times \frac{1}{2 g} \times v_{2}^{2}$ \\
\hline 3 & Pipe bending & $\varsigma_{3}=\left[0.131+0.163\left(\frac{d}{R}\right)^{7 / 2}\right]\left(\frac{\theta}{90}\right)^{1 / 2}$ & $\mathrm{~h}_{3}=\varsigma_{3} \times \frac{1}{2 g} \times v^{2}$ \\
\hline
\end{tabular}

According to the values of the coefficients of local loss in Table 2 and combined with the calculating expression (2) for route loss and local loss, the local pressure loss of mobile firefighting platform is negligible compared with the route pressure loss. While dealing with the urgency of transmission line mountain fire, the safety and rapidity of mobile firefighting platforms can be fulfilled by only calculating the route pressure loss.

\section{Portable FIRE EXTINGUISHING EQUIPMENT FIELD TEST}

\section{A. Test Condition}

Thelocationofthetestis in the Xiaoshajiangtown,Longhuicountry,HunanProvince,locatedinth enorthwestofLonghui, in

the middleeastoftheXuefengmountain.Themovingfireplatformtests tartingpointischosenatthefootofthemountainofthePufotemple,th ealtitudeofwhichis1123metersabovesealevelmeasuredbyGAR MINGPS60.Theendofthetestisatthetopofthemountain,neartheP ufotemple.Thealtitudeis1623metersabovesealevel.Andthediffer enceofthealtitudeofthetestis500meters.Measurementofthegunh eadoutletatomizationstateandpressureofdifferentaltitudecanbec ompletedinthemovingfireplatformunderdifferentoutputpressure.

\section{B. Test Data and Analysis}

TABLE III. TEST DATA OF PORTABLE FIRE EXTINGUISHING EQUIPMENT WATER PRESSURE LOSS.

\begin{tabular}{|c|c|c|c|c|c|}
\hline $\begin{array}{c}\text { head } \\
(\mathrm{m})\end{array}$ & $\begin{array}{c}\text { Water delivery } \\
\text { distance(m) }\end{array}$ & $\begin{array}{c}\text { Flow(L/ } / \\
\text { min) }\end{array}$ & $\begin{array}{c}\text { rotational } \\
\text { speed of water } \\
\text { pump } \\
\text { (r/min) }\end{array}$ & $\begin{array}{c}\text { Pressure of water } \\
\text { pump(MPa) }\end{array}$ & $\begin{array}{c}\text { Water gun } \\
\text { range(m) }\end{array}$ \\
\hline 500 & 3200 & 20.12 & 628.8 & 10.0 & 12 \\
\hline 325 & 2400 & 32.74 & 525.1 & 9.0 & 15 \\
\hline 201 & 800 & 37.93 & 474.7 & 8.0 & 12 \\
\hline $0-5$ & 30 & 20.29 & 418.8 & 6.0 & 18 \\
\hline
\end{tabular}

Table3datashowsthatwhenmobileplatformfirepumpoutletpr essureis10.0MPa,theconveyancedistancereaches $3200 \mathrm{~m}$,vertica lliftreaches500mandtipsexporthassomeatomizationpressure.Th us,themethodofmobileplatformfirepressurelosscalculationthatt hispaperusedis-

consistentwiththeresultsofthefieldtest,hasaccuracycalculation,a ndcanmeettheneedsofplatformdesignandtest,andbeabletoguidet hemobileplatforminthepracticalapplicationoffirefightingfires.T hispapersaidmobileplatformusesatomizationtipstoimprovefiree xtinguishingeffect,whenusing10MPapressurewatertotransmit3 200mandtheverticalliftis500m,thepressurecannotcompletelyato mizeextinguishingagent.Extinguishingwaterdropletsparticlesis affectedlittlebyairresistance, itsrangereaches $18 \mathrm{~m}$. Whenusing8. 0MPaand9.0MPatotransmitwater,theresidualpressurewhoselift reaches201mand325mcompletelyatomizedextinguishing.Influe ncedbyair resistance,itsrange decreasesinstead.

\section{APPLICATION OF PORTABLE FIRE EXTINGUISHING EQUIPMENT IN POWER SYSTEMS}

According to the history statistics of wildfires, massivemountain fires often occurred during the period of Tomb-sweeping Day all around China, which resulted in the trips of transmission lines and the severe threat to the safe operation of the grid[8]. During the period of Tomb-sweeping Day in 2014, State Grid Hunan Electric Power Company deployed fiveportable fire extinguishing equipment, and the total area of extinguished open fires was $3,500 \mathrm{~m}^{2}$ in April 4-5. The lines of $110 \mathrm{kV}$ and above of the Hunan grid did not suffer from the accidents of mountain fire trip, which set a record that there was no trip occurring in the Hunan grid during a norain Tomb-sweeping Day, marking a great breakthrough of the technology against wildfires of the grid, and ensured a strong support for the safe and stable operation of the large power grid. The application of the portable fire extinguishing equipment means that the characteristics of the equipmentincludes safe drive, long water-delivery distance, high lift and good performance for fire-fighting, which can solve the problems of the bad traffic at the sites of transmission line mountain fire and the tough access to water, and fill up the gap of equipmentfor transmission line mountain firefighting in China.

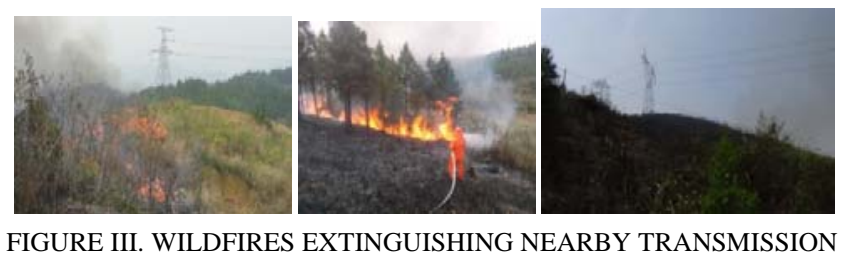
LINES.

\section{CONCLUSION}

Aiming at the existing problem that forest firenear transmission line, water delivery distance and lift, this paper analyzes the pressure loss of portable fire extinguishing equipment through the combination of theoretical calculation, wild field test and numerical simulation, which effectively guides the design and field application of portable fire extinguishing equipment and has made the conclusion that the water delivery distance of portable fire extinguishing equipment can reach $3000 \mathrm{~m}$ and the vertical lift of that can reach $500 \mathrm{~m}$ at the same time. The practical application ofportable fire extinguishing equipment in power system indicates that the equipment possesses several advantages including safety driving and user-friendly control, which has settled the problem that it is difficult for us to get water in the process of handling forest fire near transmission lines. At the meantime, it dramatically reduces the number of trip caused by forest fire related about transmission lines and has obviously enhanced the ability to defending forest fire, which has a broad application and dissemination value. 


\section{REFERENCE}

[1] Zhang Zhiguo. Prevention of forest fireshave enteredInto the era of robots[J]. Green China2013,14(7): 32-35.

[2] Ji Yongxing. High-power mist fire protection equipment-turbine spray fire engine[J]. FIRE SCIENCE AND TECHNOLOGY, 2005. 24(4): 456-459.

[3] Wang Ge, Ji Yongxing, Ni Jun. Cold aerosol fire engine and its' applications[J]. FIRE SCIENCE AND TECHNOLOGY, 2009,28(1): 5355.

[4] Liang Yong, Li Zhe, Qu Yanyan. The Polar Orbit Meteorological Satellite and Its Application in Monitoring Mountain Fire for Transmission Line[J].Henan Science. 2013,31(10): 1664-1667.

[5] Xu Limin, Xu Houqian,.Application of Unstructuted Grids in Numerical Simulation of Periodic Flow[J]. JOURNAL OF NANJING UNIVERSITY OF SCIENCE AND TECHNOLOGY(NATURAL SCIENCE). 2006,30(6): 705-708.

[6] Zhang Qiang, Yang Yong. Some Comparative Study of Turbulence Models for Fluidic Thrust Vectoring Nozzle[J].Journal of Northwestern Polytechnical University.2012,30(1): 62-67.

[7] Gan Wenbiao, Zhou Zhou. Reynolds-averaged Navier-Stokes Method with Laminar Kinetic Energy Turbulent Model[J]. Chinese Journal of Computational Physics.2013,30(2): 169-179.

[8] Lu Jiazheng, Wu Chuanping ,Yang Li, et al. Research and application of forest fire monitor and early-warning system for transmission line[J]. 2014,42(16): 89-96. 